\title{
Determination of roof rock weakening zones in extraction columns based on seismic exploration
}

\author{
Sergei Sokolov ${ }^{1}$, Anastasiya Kolmakova ${ }^{1}$, Gennady Rout ${ }^{2}$, and Peet-Mati Sööt ${ }^{3}$ \\ ${ }^{1}$ Federal Research Center for Coal and Coal Chemistry SB RAS, Kemerovo, 650000, Russia \\ ${ }^{2}$ T.F. Gorbachev Kuzbass Technical University, 650000, Kemerovo, Russia \\ ${ }^{3}$ CMM Energy LLC, Salem, 97306, OR, USA
}

\begin{abstract}
This article highlights the difficulties that arise in coal mining when roof areas have fractures with an opening of up to $0.2-0.5 \mathrm{~m}$. Such situations may cause roof collapse. The seismic exploration method used by the authors to assess the geomechanical characteristics of extraction columns is described. The results of work on identification and registration of unstable roof areas are presented.
\end{abstract}

\section{Introduction}

Mining and geological conditions of a coal deposit are one of the main factors affecting the development of the deposit. The safety and continuity of the underground coal mining process is largely determined by the technological capabilities of the equipment and the absence or presence of negative conditions within the mining section. In this case, the timely receipt of information about the state of the coal-rock massif plays an important role. At the same time, various geological aspects may have a negative impact on the coal mining process $[1,2]$.

Among these geological aspects are inclusions in poorly connected rocks, occurring in the roof area of the extraction column, as revealed in the mining at the Vladimirovskaya Mine. The coal field of this coal mining enterprise is located on the western wing of the Kedrovsko-Krokhalevskaya Brachisyncline, $30 \mathrm{~km}$ north of Kemerovo. The development of Longwalls No. 3, 5, 9, and 10 was envisaged under the former hydraulic dump of the Kedrovsky Open-Cast Mine, into which a rock dump was formed. This created an alluvial mass as a result of the slurry from the stripping operations at the Kedrovsky Mine. This occurred between 1950 and 60. Development of the Vladimirovsky Seam with longwalls in the Vladimirovskaya Mine was supposed to be in the depth interval of 20-50 m from the surface, in the zone of weakened, weathered rocks. In the course of longwall mining, when approaching the surface, Quaternary sediments and the dump bottom fell into the roof rock collapse zone.

Considering mining and geological conditions within the mine field and the physical and mechanical properties of the alluvial mass (determined during drilling of 3 boreholes

\footnotetext{
* Corresponding author: sokolov@uglemetan.ru
} 
located on the border of the partially drained former hydraulic dump), it was recommended to mine excavation areas using the KMYU4U 22/42 equipment that possesses $2.5 \mathrm{~m}-2.7 \mathrm{~m}$ of removable capacity directly under the dump.

Excavation of experimental site reserves in the presence of highly unstable roof rocks should have been carried out while leaving 1.0-1.5 m of coal in place. The recommended advance speed of the face was due to the necessity for leading the longwall face line relative to the fracture propagation boundary in the steep slope of the face, and this speed had to be at least $4-5 \mathrm{~m} /$ day.

Driving, maintenance of workings, development of entries and longwall mining were carried out in accordance with the "Temporary instructions for the management of rock pressure in working faces in coal seams of up to $3.5 \mathrm{~m}$ capacity and with an angle of dip up to $35^{\circ}$ ", not allowing a "domed roof" [3].

Despite the implementation of the recommended set of measures, during the development of Vladimirovsky coal seam reserves, collapses occurred in Longwalls No. 3, 5, 9 and 10 with significant falls of roof rock. The mining operations in the Extraction Column (EC) No. 10 (length along dip of $92 \mathrm{~m}$, along strike of $370 \mathrm{~m}$; the depth of mining operations from the surface from $30 \mathrm{~m}$ to $70 \mathrm{~m}$ ) were characterized by extreme difficulties. During EC No. 10 mining, periodic collapses lasting up to 5 minutes were observed. As a result of one of them, more than $80 \%$ of the space to the face zone of the longwall was blocked by crumbling tuff conglomerate, and the face conveyor and the shearer were partially backfilled.

\section{Methodologies}

The presence of unstable roof areas reduces the safety level, mining operations rate and complicates the processes of coal mining and support of mine workings. Taking into account the incidents that occurred, additional survey of roof conditions was worked out to mine the EC No. 11 that has similar mining and geological conditions to those of EC No. 10. Considering the distance between exploration wells, the probability of registering inclusions of tuff conglomerates with an average size of 10 by $10 \mathrm{~m}$ in the roof, was initially rather low based on the results of drilling, In this case, in order to ensure the safe mining operations, it was necessary to carry out clarifying measurements that would allow adjusting the mining plans taking into account areas of unstable roof in order to avoid further downtime of mining equipment and reduce the risk of emergencies associated with unforeseen roof collapse. For this, a seismic exploration survey was performed from the surface of a coal-rock massif, which is an effective tool for engineering mapping. This makes it possible to determine physical and mechanical properties of geological layers making up the rock mass.

In the period from October 20, 2010 to December 5, 2010, field seismic measurements, processing and interpretation of the obtained data were carried out. Seismic exploration was carried out within longwall No. 11 of the Vladimirskaya Mine in order to determine the roof rock state and register zones with poorly bound rocks. To implement the measurements, the method of common depth point (CDP) was used, based on the registration of reflected elastic waves, artificially excited on the surface by an oscillation source $[4,5]$.

In 2D - CDP modification, information is recorded along the lines of geophysical profiles under surface areas containing an ordered, interval-distributed system of seismic receivers [6]. The survey process as part of the seismic profiling includes 2 main stages: 
1. Field work:

- associating profiles with the terrain, selection of equipment and measurement parameters;

- placement of field seismic equipment;

- initiation and registration of signals.

2. Office work:

- preprocessing and analysis of registered information;

- data processing;

- interpretation of results.

Seismic exploration was carried out on 5 geophysical profiles with a total length of $1,150 \mathrm{~m}$. The location of the seismic profiles on the surface was based on their location relative to the EC No. 11 outline (Fig. 1).

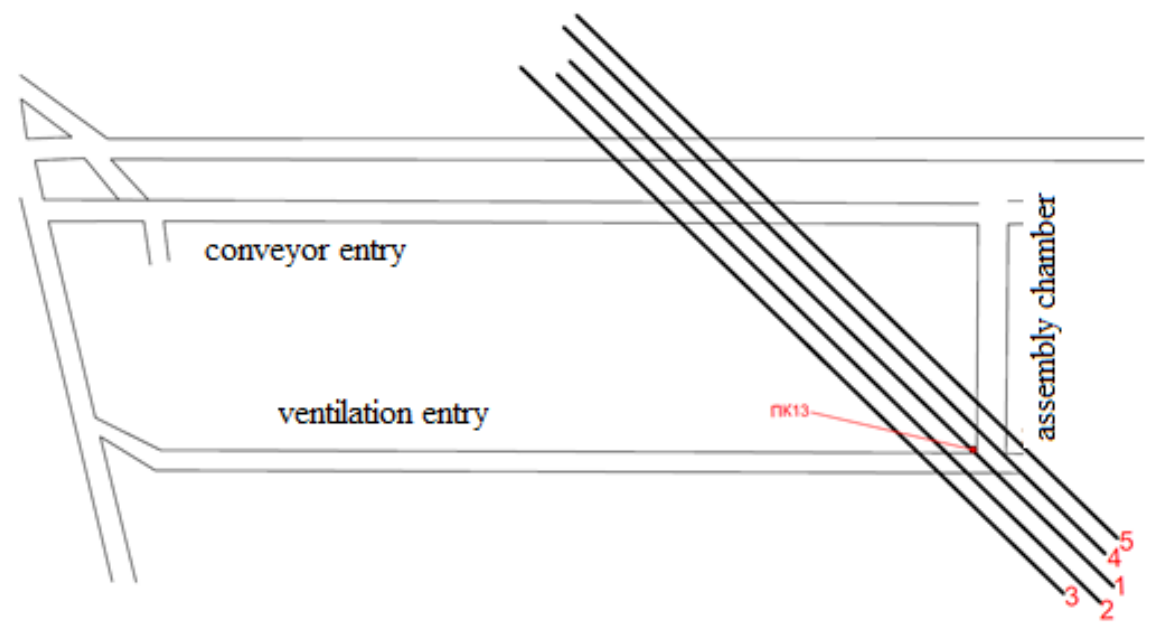

Fig. 1. Scheme of geophysical profiles arrangement during the longwall No. 11 study.

For geophysical surveying, field seismic equipment was used, consisting of a source and receivers of seismic vibrations, as well as seismic recording stations. Two seismic stations "Lakkolit 24-M3" were used as data recording units, allowing 48-channel data recording. During the surveys, seismic stations recorded data that was received from groups of geophones GS-20 DX

Seismic vibrations were generated by a source of elastic waves from an active element a 12-gauge blank cartridge filled with smokeless powder. The following parameters were used to register waves under impulse action: step between receiving points $-5 \mathrm{~m}$; step between pickets of vibration excitation $-5 \mathrm{~m}$; number of recordings -1 .

General measurement parameters configured for the measuring equipment are defined with the following values: sampling step -0.5 ; cutoff of the built-in filter $1000 \mathrm{~Hz}$; the real reception interval is $1,536 \mathrm{~m}$. Based on the results of field measurements, 132 seismic wavefield patterns were recorded with a 48 -channel array of seismic receivers.

\section{Results and discussion}

In order to form the resulting seismic section, which would reflect the occurrence pattern of the studied geological elevation data, processing was performed. The processing of seismic information by the method of reflected waves was carried out in several stages. The first 
stage included: creation and registration of the project; assigning the geometry of the observation system profile and entering it into the database; loading of seismic data.

The second stage involved: analysis of the wave field in order to determine the amplitude-frequency spectrum of the recording, identification of interference waves; selection of filtering parameters applied to the original records in order to suppress interference waves; selection of a high-speed law and entering it into the database; editing seismic records while entering the revised files into the database; selection of muting parameters; summation by common depth point method (CDPM). At the final stage, the time section was migrated into the deep section.

Based on the office work results, seismic sections were obtained, on which a repeating in-phase axis was recorded, with an estimated depth of 45-50 m. This was established as a reflection of the Vladimirovsky Coal Seam. During the assessment of seismic sections, it was found that it is not possible to visually determine the position of the roof sections containing conglomerate inclusions. In this regard, the amplitude-frequency characteristics of the recorded seismic signal were studied [7]

Differentiation of various wave parameters was observed within the considered waveguide, which is the Vladimovskiy Coal Seam, where the greatest contrast, ensuring the reliability of the research results, was recorded when analyzing the change in seismic vibrations amplitudes (Fig. 2).

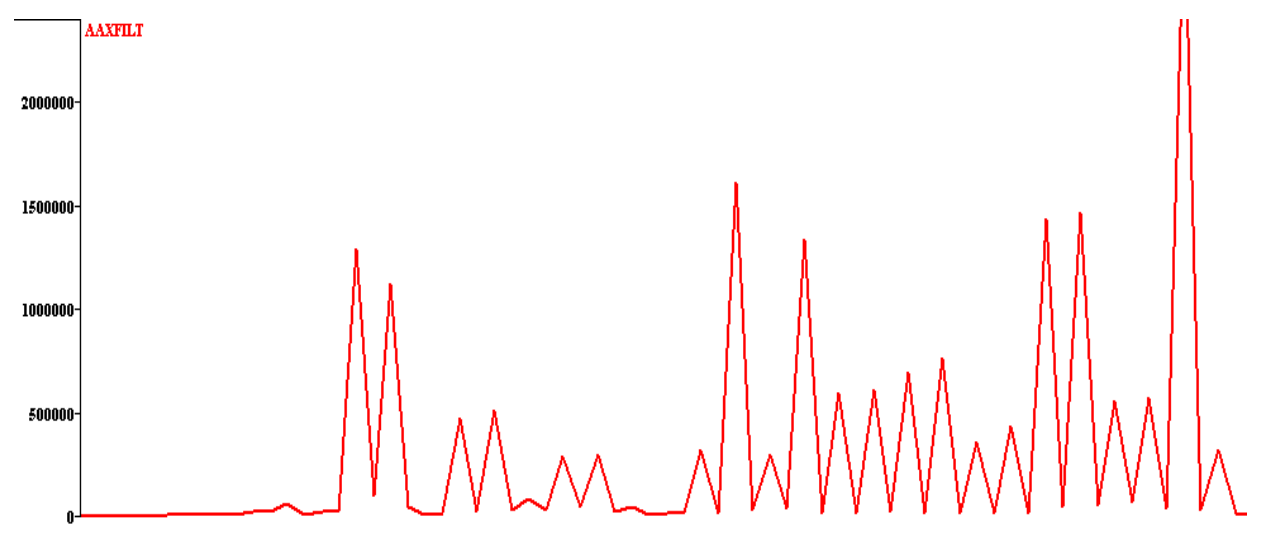

Fig. 2. Amplitude analysis of the active roof area within the geophysical profile No. 1.

Based on the study results of the space between the recorded reflections of coal seams, the areas of concentration of rocks with the least connectivity were determined along geophysical profiles 1-4. On the generated seismic sections, the following elements of the massif structure were identified (Fig. 3): Vladimirovsky Coal Seam with an average burial depth of about 50 meters (black color); boundaries of areas characterized by minimum amplitudes values (purple color); boundaries of areas characterized by small values of amplitudes, which, under certain conditions, can also be areas of unstable roof (blue color).

Based on the geophysical measurements results comparing with the actual position of the functioning objects of Vladimirovskaya mine, zones, characterized by the minimum values of amplitudes and small values of amplitudes, were placed on the mining plan in the contour of the EC No. 11 (Fig. 4). 


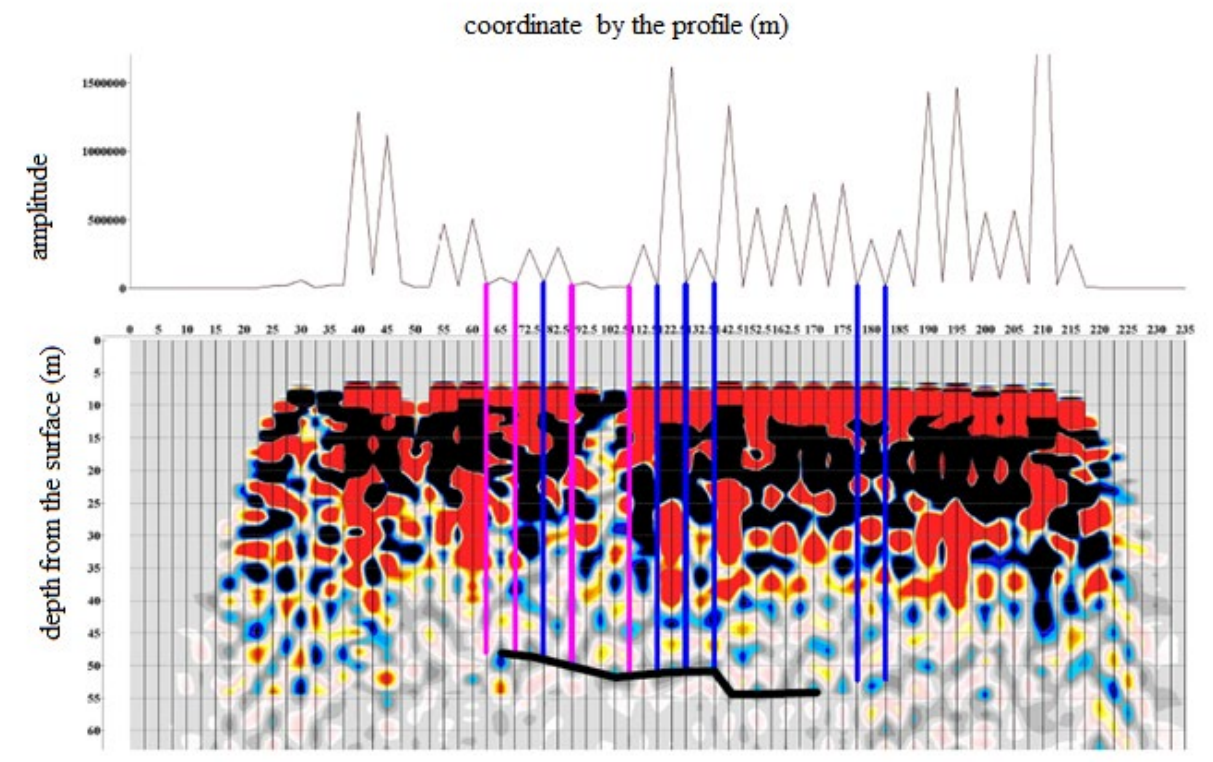

Fig. 3. The results of geophysical measurements of the area of the extraction column No. 11.

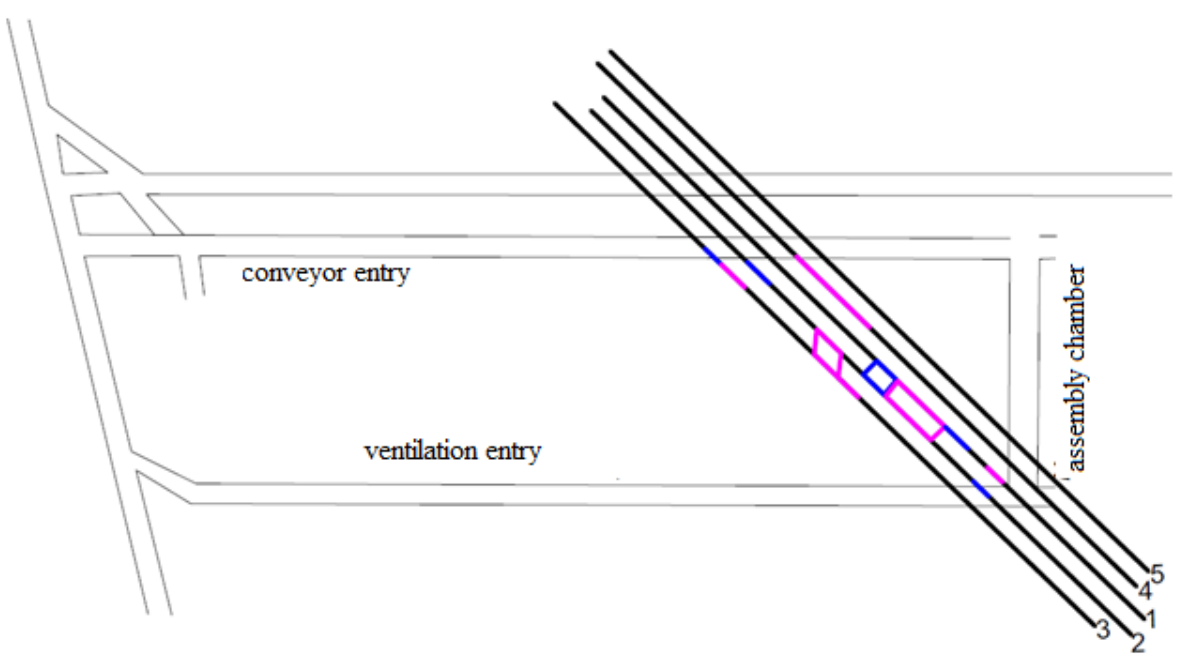

Fig. 4. The results of geophysical measurements plotted on the mining work plan of "Vladimirovskaya" mine.

\section{Conclusion}

Subsequently, within the areas identified according to the results of seismic exploration, the measures for the immediate roof strengthening with the resin injection were implemented. As a result of their implementation, mining operations in the zone of hydraulic dump influence were carried out without forced stops. The success of mining in the studied section of longwall No. 11 after resin injection reinforcement indicates high efficiency of seismic exploration use as a tool for registering zones of fractured rocks in the roof area of extraction column. 


\section{References}

1. M.V. Shinkevich, GIAB, 6, 278-285 (2013)

2. E.N. Kozyreva, GIAB, 9, 322-325 (2011)

3. Temporary instructions for the management of rock pressure in working faces in seams with up to $3.5 \mathrm{~m}$ thickness and an angle of dip up to $35^{\circ}$ "L. (VNIMI, 1982)

4. O.V.Tailakov, V.I. Ovchinnikov, S.V. Sokolov, Geotechnical Mech., 88, 22-26 (2010)

5. O.V. Tailakov, S.V. Sokolov, et al., Bulletin of the Scientific Center for the Safety of Work in the Coal Industry, 4, 34-37 (2015)

6. G.N. Boganik, I.I. Gurvich, Seismic exploration (Publishing house AIS, 2006)

7. O.V. Tailakov, S.V. Sokolov, et. al., Mining Information and Analytical Bulletin, S49, 300-312 (2018) 